\title{
Changes in the Use Intention of Digital Wellness Technologies and Its Antecedents Over Time: The Use of Physical Activity Logger Applications Among Young Elderly in Finland
}

\author{
Markus Makkonen \\ ${ }^{1}$ Institute for Advanced \\ Management Systems Research \\ ${ }^{2}$ University of Jyvaskyla \\ markus.v.makkonen@jyu.fi
}

\author{
Tuomas Kari \\ ${ }^{1}$ Institute for Advanced \\ Management Systems Research \\ ${ }^{2}$ University of Jyvaskyla \\ tuomas.t.kari@j.jyu.fi
}

\author{
Lauri Frank \\ University of Jyvaskyla \\ lauri.frank@jyyu.fi
}

\begin{abstract}
Physical inactivity has become a prevalent problem among elderly people. Although digital wellness technologies have been proposed as one promising solution to it, our understanding on the antecedents of the acceptance and use of these technologies among elderly people remains limited. In this study, our objective is to promote this understanding by examining the potential changes in the use intention of digital wellness technologies and its antecedents over time in the case of the young elderly segment and physical activity logger applications. We base this examination theoretically on UTAUT2 and empirically on survey data that is collected from 99 Finnish young elderly users of a physical activity logger application and analysed with partial least squares structural equation modelling (PLSSEM). We find the scores of both use intention and most of its antecedents to decline over time as well as some changes in the effects of the antecedents on use intention.
\end{abstract}

\section{Introduction}

Although regular physical activity and the avoidance of sedentary lifestyle have been found to provide considerable health benefits also in older age [1], many elderly people fail to meet the physical activity guidelines recommended by public health agencies, such as the World Health Organisation [2], [3]. During the past year, this physical inactivity problem and its detrimental impact on health have likely been further exacerbated by the coronavirus disease 2019 (COVID-19) pandemic caused by the severe acute respiratory syndrome coronavirus 2 (SARS-CoV-2) [4]-[7], which has limited the possibilities for physical activity particularly among the elderly population. Therefore, new and innovative ways to promote the levels of physical activity among elderly people are urgently needed. One way to achieve this are different types of digital wellness technologies, such as smartphone and smartwatch applications for tracking one's health and well-being in everyday life. These have been found very promising in terms of promoting the levels of physical activity not only among young people but also among elderly people [8]-[12], although more high-quality studies especially on their long-term effects are still called for. In addition to elderly people in general, their potential has been highlighted particularly in the more specific segment of young elderly [13]-[23], which consists of people aged approximately $60-75$ years.

However, despite their promising status as a solution to the aforementioned physical inactivity problem, there is a lack of prior studies on the antecedents of the acceptance and use of digital wellness technologies among elderly people. This applies especially to longitudinal studies that examine how the use of the technologies evolves after their initial acceptance. Longitudinal study settings can be considered particularly important in the context of digital wellness technologies because, as it is suggested in theories like the lived informatics model of personal informatics [24], the use of these technologies, especially those aimed at selftracking, is often characterised by "lapses" in their use. This suggests that the intention to use the technologies and its antecedents do not remain constant but change over time. However, in prior information systems (IS) literature, such changes have not been studied from the perspective of technology acceptance and use.

The objective of this present study is to address this gap in prior research by studying how the use intention of digital wellness technologies and its antecedents among elderly people potentially change over time. We examine this research question in the case of the young elderly segment and one common type of digital wellness technology: physical activity logger applications. By physical activity logger applications, we refer to 
mobile applications that enable users to log and keep track of their physical activities in everyday life as well as view different types of reports about them. The data about the physical activities may be entered to the application manually by the users or it may be measured automatically by the application itself or by other applications or devices, from which it is then transferred to the application in question.

As the theoretical foundation for conceptualising the antecedents of the intention to use physical activity logger applications and formulating the research model for examining the changes in use intention and its antecedents over time, we use UTAUT2 [25], which is one of the most comprehensive and established IS theories for explaining technology acceptance and use in consumer contexts, such as the one of this study. In turn, as the empirical data for the examination, we use survey data that is collected from 99 Finnish young elderly users of a physical activity logger application in two subsequent time points and analysed with partial least squares structural equation modelling (PLS-SEM).

After this introductory section, we describe the research setting and the research model of the study in Sections 2 and 3. This is followed by a description of the research methodology and reporting of the research results in Sections 4 and 5. The results are discussed in more detail in Section 6. Finally, we conclude the paper with a discussion about the limitations of the study and potential paths of future research in Section 7 .

\section{Research setting}

This study was conducted as part of a broader research program that uses digital wellness technology to study and promote the physical activity of young elderly in Finland. The multiyear and nationwide program is conducted in close co-operation with Finnish pensioners' associations, which are responsible for recruiting volunteer participants to the program amongst their members. In the program, the interaction between the researchers and the participants takes place mainly in group meetings of about 20-50 participants and one or two researchers, although during the COVID-19 pandemic, most of these face-to-face meetings have been replaced with online interaction. The first three of the meetings take place during the first few weeks of participation. This is followed by multiple successive selftracking periods of about four to six months, during which the participants are asked to use a physical activity logger application in their everyday life to collect data about their actual physical activity. At the end of each self-tracking period, there is another meeting in which follow-up data is collected. The application, like participating in the program itself, is free for the partic- ipants. However, the participants are required to own a smartphone on which the application can be installed.

The application is developed by the research program itself on top of the Wellmo [26] platform, and it is available for both Google's Android and Apple's iOS operating systems. In the group meetings, the participants are trained to use the application and instructed to conduct the logging manually by entering the type, intensity, time, and duration of their physical activities. The application also has the ability to extract this data automatically from other applications, such as Google Fit and Apple Health. However, the participants are not instructed to take this feature into use, which is why only few actually use it. Based on the logged data, the application also shows the users different types of reports about their physical activity.

\section{Research model}

As already mentioned in the introduction, the research model of this study is founded on UTAUT2 by Venkatesh et al. [25], which is an extension of the unified theory of acceptance and use of technology (UTAUT) by Venkatesh et al. [27] from organisational contexts to consumer contexts. UTAUT2 has been applied to explain technology acceptance and use in various IS contexts, including also the context of mobile health and fitness applications and devices [28]-[32] as well as the context of elderly users [33]. However, none of these prior studies have combined the two contexts by examining, for example, the acceptance and use of physical activity logger applications among young elderly, as it is done in this study.

In UTAUT2, the behavioural intention (BI) to use a particular technology is hypothesised to be positively affected by seven antecedent constructs [25]: performance expectancy (PE - i.e., the degree to which using a technology will provide benefits to consumers in performing certain activities), effort expectancy (EE i.e., the degree of ease associated with consumers' use of technology), social influence (SI - i.e., the extent to which consumers perceive that important others believe they should use a particular technology), facilitating conditions (FC - i.e., consumers' perceptions of the resources and support available to perform a behaviour), hedonic motivation (HM - i.e., the fun or pleasure derived from using a technology), price value (PV - i.e., the consumers' cognitive trade-off between the perceived benefits of using the technology and the monetary cost for using it), and habit (HT - i.e., the extent to which people tend to perform behaviours automatically because of learning). In addition, UTAUT2 also hypothesises three moderators for the effects of these seven antecedent constructs on use intention: age, 
gender, and experience. However, because of the limited number of participants in our research program at the time of conducting the present study, these moderators are omitted from the research model. In addition, we omit two of the seven antecedent constructs: facilitating conditions and price value. These were considered irrelevant in the present research setting because the application was free for all the participants and they all had the same resource requirements for taking part in the program (i.e., owning a smartphone) as well as were given the same training and support for setting up and using the application, thus likely resulting in very low variance in their perceptions of these issues. Finally, our research model also focuses on explaining only use intention and not actual use behaviour. The research model, with the omitted constructs and effects presented as dashed, is illustrated in Figure 1.

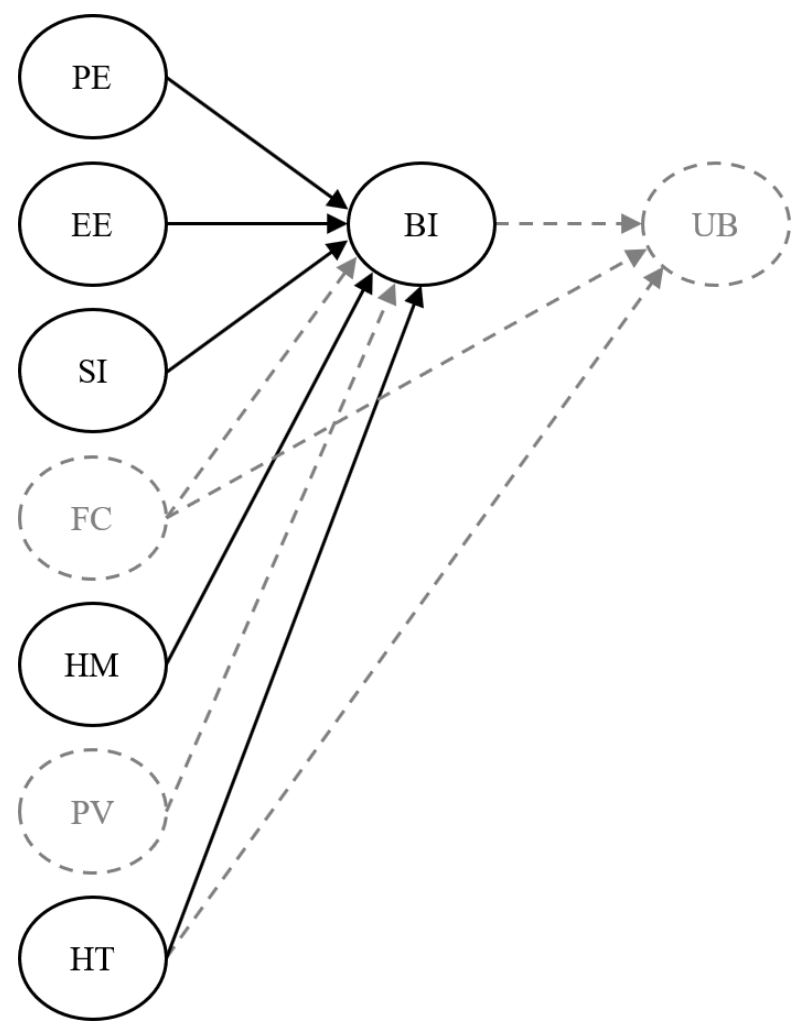

Figure 1. Research model

\section{Methodology}

The data for the study was collected from the participants of our research program in two subsequent surveys, which were conducted in autumn 2019 after about four months of using the application and in summer 2020 after about 12 months of using the application. In the remainder of this paper, these two time points, respectively, are referred to as $\mathrm{T} 1$ and $\mathrm{T} 2$. The first survey was administered as a pen-and-paper survey in a group meeting, whereas the second survey was administered as an online survey due to the COVID-19 pandemic. Because Finland has two official languages, the participants had the option to respond to the surveys in either Finnish or Swedish. In the surveys, each construct of the research model was measured reflectively by three indicators, which were all adapted from [25]. Their wordings in English are reported in Table 1. The measurement scale was a seven-point Likert scale ranging from one (strongly disagree) to seven (strongly agree). In order to avoid forced responses, the participants also had the option not to respond to a particular item, which resulted in a missing value.

Table 1. Indicator wordings

\begin{tabular}{|c|c|}
\hline Item & Wording \\
\hline PE1 & $\begin{array}{l}\text { I find the app useful in achieving my daily } \\
\text { exercise goals. }\end{array}$ \\
\hline PE2 & $\begin{array}{l}\text { Using the app helps me achieve my exercise } \\
\text { goals more quickly. }\end{array}$ \\
\hline PE3 & $\begin{array}{l}\text { Using the app increases my efficiency in } \\
\text { achieving my exercise goals. }\end{array}$ \\
\hline EE1 & $\begin{array}{l}\text { Learning how to use the app to achieve my } \\
\text { exercise goals is easy for me. }\end{array}$ \\
\hline EE2 & $\begin{array}{l}\text { I find using the app to achieve my exercise } \\
\text { goals easy. }\end{array}$ \\
\hline EE3 & $\begin{array}{l}\text { It is easy for me to become skilful at using } \\
\text { the app to achieve my exercise goals. }\end{array}$ \\
\hline SI1 & $\begin{array}{l}\text { People who are important to me think that I } \\
\text { should use the app to achieve my exercise goals. }\end{array}$ \\
\hline SI2 & $\begin{array}{l}\text { People who influence my behaviour think that I } \\
\text { should use the app to achieve my exercise goals. }\end{array}$ \\
\hline SI3 & $\begin{array}{l}\text { People whose opinions I value prefer that I use } \\
\text { the app to achieve my exercise goals. }\end{array}$ \\
\hline HM1 & $\begin{array}{l}\text { Using the app to achieve my exercise goals } \\
\text { is fun. }\end{array}$ \\
\hline HM2 & $\begin{array}{l}\text { Using the app to achieve my exercise goals } \\
\text { is enjoyable. }\end{array}$ \\
\hline HM3 & $\begin{array}{l}\text { Using the app to achieve my exercise goals } \\
\text { is entertaining. }\end{array}$ \\
\hline HT1 & $\begin{array}{l}\text { The use of the app to achieve my exercise } \\
\text { goals has become a habit for me. }\end{array}$ \\
\hline HT2 & $\begin{array}{l}\text { I am addicted to using the app to achieve } \\
\text { my exercise goals. }\end{array}$ \\
\hline HT3 & $\begin{array}{l}\text { I must use the app to achieve my exercise } \\
\text { goals. }\end{array}$ \\
\hline BI1 & $\begin{array}{l}\text { I intend to continue using the app to achieve } \\
\text { my exercise goals. }\end{array}$ \\
\hline BI2 & $\begin{array}{l}\text { I will always try to use the app to achieve } \\
\text { my exercise goals. }\end{array}$ \\
\hline BI3 & $\begin{array}{l}\text { I plan to use the app regularly to achieve } \\
\text { my exercise goals. }\end{array}$ \\
\hline
\end{tabular}


Due to the limited sample size, the collected data was analysed with variance-based structural equation modelling (VB-SEM), more specifically partial least squares structural equation modelling (PLS-SEM). As a statistical tool, we used the SmartPLS version 3.3.2 software [34]. In addition, we followed carefully the previously published guidelines for conducting PLSSEM in IS research [35]. For example, in accordance with the given guidelines, we used mode $\mathrm{A}$ as the indicator weighting mode of the constructs, path weighting as the weighting scheme, +1 as the initial weights, and $<10^{-7}$ as the stop criterion in model estimation, whereas the statistical significance of the model estimates was tested by using bootstrapping with 5,000 subsamples. As the threshold for statistical significance, we used $p<0.05$. The potential missing values were handled by using mean replacement.

The estimated model consisted of two submodels, which were otherwise identical and formulated based on the research model illustrated in Figure 1 but of which one was estimated by using the data collected at $\mathrm{T} 1$ and the other one by using the data collected at $\mathrm{T} 2$. The two submodels were also connected by so-called carry-over effects [36], which were used to examine how the scores of a specific construct at T1 affect the scores of that same construct at T2. After estimating the model and evaluating the reliability and validity of its submodels at both construct and indicator levels, the potential changes in the construct scores and effect sizes from $\mathrm{T} 1$ to $\mathrm{T} 2$ were examined. This examination followed the procedure proposed by Roemer [36] for evolution models with panel data (also referred to as model type A.1 in her paper). First, the statistical significance of the changes in the means of unstandardised construct scores from T1 to T2 was tested by using the parametric Student's paired samples t-test. Its results were additionally confirmed by using the nonparametric Wilcoxon [37] signed-rank test if the compared means were not found to be normally distributed as suggested by the Shapiro-Wilk [38] test. Second, the estimated size of each effect at T1 was compared against the 95\% bias-corrected and accelerated (BCa) confidence interval [39] of the estimated size of that same effect at $\mathrm{T} 2$. If the estimate at $\mathrm{T} 1 \mathrm{did}$ not fall within the confidence interval of the estimate at $\mathrm{T} 2$, then the change in the effect size could be considered as statistically significant.

\section{Results}

In total, 115 participants provided valid responses to the survey at $\mathrm{T} 1$, and some initial results concerning this sample have already been reported in [40]. Of them, 99 participants provided valid responses also to the survey at $\mathrm{T} 2$, resulting in a drop-out rate of about $13.9 \%$ and a sample size of 99 participants to be used in this study. The descriptive statistics of this sample in terms of the gender, age, and response language of the participants as well as a subjective assessment of their level of physical activity are reported in Table 2. As can be seen, two-thirds of the respondents were women, and over nine out of ten assessed their level of physical activity as moderate or higher. The age of the respondents ranged from 49 to 79 years, with a mean of 69.1 years and a standard deviation of 4.7 years. Although there were also some respondents who were slightly younger or older than our target young elderly segment consisting of people aged approximately 60 75 years, we decided not to omit these respondents from the study due to our limited sample size.

Table 2. Sample statistics ( $\mathbf{N}=99)$

\begin{tabular}{|l|c|c|}
\hline & N & \% \\
\hline Gender & & \\
\hline Man & 34 & 34.3 \\
\hline Woman & 65 & 65.7 \\
\hline Age & & \\
\hline Under 60 years & 2 & 2.0 \\
\hline 60-64 years & 10 & 10.1 \\
\hline 65-69 years & 39 & 39.4 \\
\hline $70-74$ years & 35 & 35.4 \\
\hline 75 years or over & 13 & 13.1 \\
\hline Language & & \\
\hline Finnish & 63 & 63.6 \\
\hline Swedish & 36 & 36.4 \\
\hline Level of physical activity & & \\
\hline Very high & 1 & 1.0 \\
\hline High & 16 & 16.2 \\
\hline Moderate & 73 & 73.7 \\
\hline Low & 3 & 3.0 \\
\hline Very low & 6 & 6.1 \\
\hline Totally passive & 0 & 0.0 \\
\hline
\end{tabular}

\subsection{Estimation results}

The estimation results of submodels $\mathrm{T} 1$ and $\mathrm{T} 2$, respectively, in terms of the standardised size and statistical significance of the effects of the antecedent constructs on behavioural intention as well as the proportion of explained variance $\left(\mathrm{R}^{2}\right)$ in the behavioural intention construct are reported in Figures 2 and 3. At T1, performance expectancy, hedonic motivation, and habit were found to have a positive and statistically significant effect on behavioural intention, whereas the 
effects of effort expectancy and social influence were found as statistically not significant. At T2, in addition to hedonic motivation and habit, also effort expectancy was found to have a positive and statistically significant effect on behavioural intention, whereas the effects of performance expectancy and social influence were found as statistically not significant. In terms of explanatory power, submodel T2 performed slightly better by being able to explain $76.5 \%$ of the variance in behavioural intention. However, also submodel T1 performed very well by being able to explain $71.4 \%$ of the variance in behavioural intention.

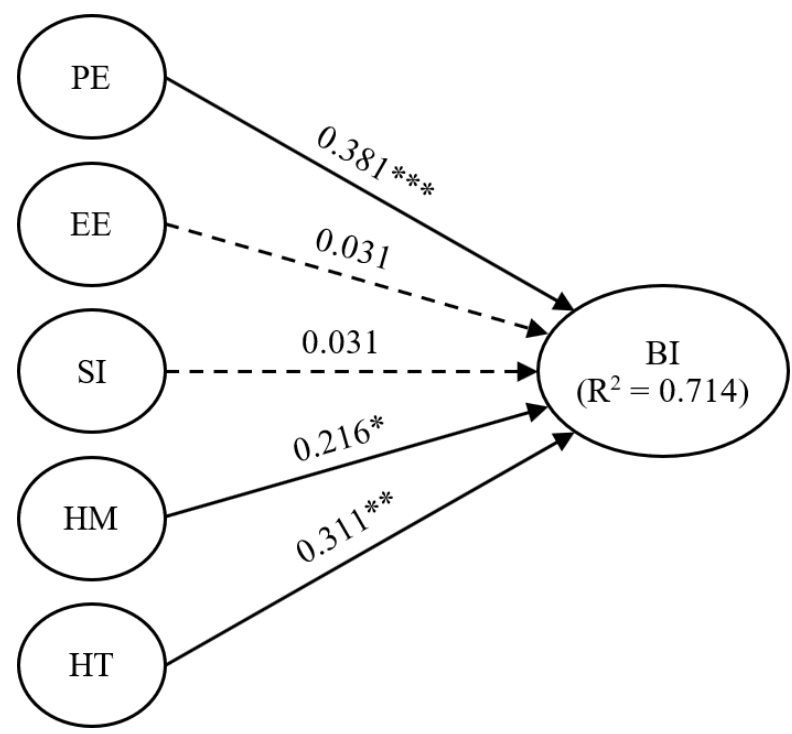

Figure 2. Estimation results of submodel T1 $\left.{ }^{* \star \star}=p<0.001,{ }^{\star \star}=p<0.01,{ }^{*}=p<0.05\right)$

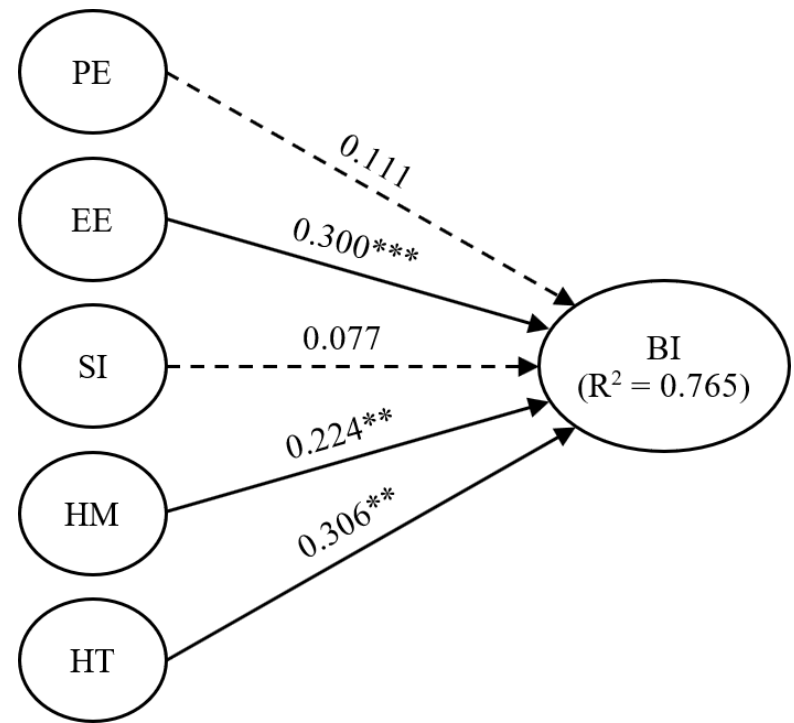

Figure 3. Estimation results of submodel T2 $\left(^{\star \star \star}=p<0.001,{ }^{\star \star}=p<0.01,{ }^{*}=p<0.05\right)$
In terms of the carry-over effects between the constructs of the two submodels, Table 3 reports the standardised size and statistical significance of each effect as well as the proportion of explained variance $\left(\mathrm{R}^{2}\right)$ in the scores of a specific construct at $\mathrm{T} 2$ by the scores of that same construct at T1. As can be seen, in the case of performance expectancy, social influence, hedonic motivation, and habit, the scores of each construct at T1 were able to explain about $19-28 \%$ of the variance in the scores of that same construct at $\mathrm{T} 2$, meaning that there was considerable continuity in the evaluations concerning these four constructs between the two time points. In contrast, the scores of effort expectancy at $\mathrm{T} 1$ were able to explain only about $12 \%$ of the variance in the scores of effort expectancy at $\mathrm{T} 2$. Finally, when taking into account the effects of the antecedent constructs, the scores of behavioural intention at $\mathrm{T} 1$ were able to explain only about $4 \%$ of the variance in the scores of behavioural intention at $\mathrm{T} 2$. Unlike the other five carry-over effects, the carry-over effect concerning behavioural intention was also found as statistically not significant.

\section{Table 3. Carry-over effects from T1 to T2}

\begin{tabular}{|l|c|c|}
\hline Effect & Estimate & $\mathbf{R}^{2}$ by T1 at T2 \\
\hline $\mathrm{PE}_{\mathrm{T} 1} \rightarrow \mathrm{PE}_{\mathrm{T} 2}$ & $0.440^{* * *}$ & 0.194 \\
\hline $\mathrm{EE}_{\mathrm{T} 1} \rightarrow \mathrm{EE}_{\mathrm{T} 2}$ & $0.347^{* *}$ & 0.120 \\
\hline $\mathrm{SI}_{\mathrm{T} 1} \rightarrow \mathrm{SI}_{\mathrm{T} 2}$ & $0.525^{* * *}$ & 0.275 \\
\hline $\mathrm{HM}_{\mathrm{T} 1} \rightarrow \mathrm{HM}_{\mathrm{T} 2}$ & $0.456^{* * *}$ & 0.208 \\
\hline $\mathrm{HT}_{\mathrm{T} 1} \rightarrow \mathrm{HT}_{\mathrm{T} 2}$ & $0.463^{* * *}$ & 0.214 \\
\hline $\mathrm{BI}_{\mathrm{T} 1} \rightarrow \mathrm{BI}_{\mathrm{T} 2}$ & 0.106 & 0.044 \\
\hline
\end{tabular}

\subsection{Construct reliability and validity}

Construct reliabilities were evaluated by examining the composite reliability (CR) of each construct [41], which are commonly expected to be greater than or equal to 0.7 [42]. The CR of each construct is reported in the first column of Tables 4 and 5, respectively, for submodels T1 and T2. As the reported values show, all the constructs met this criterion at both $\mathrm{T} 1$ and $\mathrm{T} 2$. In turn, construct validities were evaluated by examining the convergent and discriminant validities of the constructs by using the two criteria based on the average variance extracted (AVE) of each construct [41], which refers to the average proportion of variance that a construct explains in its indicators.

In order to exhibit satisfactory convergent validity, the first criterion expects that each construct should have an AVE of at least 0.5. This means that, on average, each construct should explain at least half of the observed variance in its indicators. The AVE of each construct at T1 and T2 is reported in the second col- 
umn of Tables 4 and 5, respectively, showing that all the constructs met also this criterion at both $\mathrm{T} 1$ and $\mathrm{T} 2$. In turn, in order to exhibit satisfactory discriminant validity, the second criterion expects that each construct should have a square root of AVE greater than or equal to its absolute correlation with the other model constructs. This means that, on average, each construct should share at least an equal proportion of variance with its indicators than it shares with these other model constructs. The square root of AVE of each construct at T1 and T2 (on-diagonal cells) and the correlations between the constructs (off-diagonal cells) at T1 and $\mathrm{T} 2$ are reported in the remaining columns of Tables 4 and 5, respectively, showing that this criterion was also met by all the constructs at both $\mathrm{T} 1$ and $\mathrm{T} 2$.

Table 4. Construct statistics of submodel T1

\begin{tabular}{|l|c|c|c|c|c|c|c|c|}
\hline & CR & AVE & PE & EE & SI & HM & HT & BI \\
\hline PE & 0.908 & 0.767 & 0.876 & & & & & \\
\hline EE & 0.871 & 0.692 & 0.440 & 0.832 & & & & \\
\hline SI & 0.928 & 0.811 & 0.500 & 0.256 & 0.901 & & & \\
\hline HM & 0.926 & 0.807 & 0.674 & 0.468 & 0.527 & 0.898 & & \\
\hline HT & 0.814 & 0.595 & 0.705 & 0.477 & 0.475 & 0.673 & 0.771 & \\
\hline BI & 0.902 & 0.755 & 0.776 & 0.456 & 0.491 & 0.714 & 0.755 & 0.869 \\
\hline
\end{tabular}

Table 5. Construct statistics of submodel T2

\begin{tabular}{|l|c|c|c|c|c|c|c|c|}
\hline & CR & AVE & PE & EE & SI & HM & HT & BI \\
\hline PE & 0.892 & 0.733 & 0.856 & & & & & \\
\hline EE & 0.879 & 0.707 & 0.527 & 0.841 & & & & \\
\hline SI & 0.867 & 0.686 & 0.516 & 0.428 & 0.828 & & & \\
\hline HM & 0.901 & 0.752 & 0.733 & 0.527 & 0.376 & 0.867 & & \\
\hline HT & 0.865 & 0.681 & 0.747 & 0.543 & 0.472 & 0.655 & 0.825 & \\
\hline BI & 0.914 & 0.780 & 0.743 & 0.707 & 0.498 & 0.725 & 0.771 & 0.883 \\
\hline
\end{tabular}

\subsection{Indicator reliability and validity}

Indicator reliabilities and validities were evaluated by using the standardised loading of each indicator, which are reported for submodels T1 and T2 in Tables 6 and 7, respectively, together with the mean and standard deviation (SD) of the indicator scores as well as the percentage of missing values. In the typical case where each indicator loads on only one construct, it is commonly expected that the standardised loading of each indicator should be statistically significant and greater than or equal to 0.707 [41]. This is equal to the standardised residual of each indicator being less than or equal to 0.5 , meaning that at least half of the variance in each indicator is explained by the construct on which it loads. As the reported values show, all the indicators met this criterion at both $\mathrm{T} 1$ and $\mathrm{T} 2$.
Table 6. Indicator statistics of submodel T1

\begin{tabular}{|l|c|c|c|c|}
\hline & Mean & SD & Missing & Loading \\
\hline PE1 & 5.660 & 1.448 & $5.1 \%$ & $0.867 * * *$ \\
\hline PE2 & 5.291 & 1.548 & $13.1 \%$ & $0.895 * * *$ \\
\hline PE3 & 5.215 & 1.559 & $6.1 \%$ & $0.865 * * *$ \\
\hline EE1 & 6.299 & 1.156 & $2.0 \%$ & $0.817 * * *$ \\
\hline EE2 & 6.125 & 1.199 & $3.0 \%$ & $0.868 * * *$ \\
\hline EE3 & 5.694 & 1.516 & $1.0 \%$ & $0.809 * * *$ \\
\hline SI1 & 4.321 & 2.123 & $21.2 \%$ & $0.918^{* * *}$ \\
\hline SI2 & 4.577 & 2.095 & $28.3 \%$ & $0.917 * * *$ \\
\hline SI3 & 5.278 & 1.761 & $20.2 \%$ & $0.865 * * *$ \\
\hline HM1 & 5.731 & 1.235 & $6.1 \%$ & $0.926 * * *$ \\
\hline HM2 & 5.889 & 1.065 & $9.1 \%$ & $0.877 * * *$ \\
\hline HM3 & 5.124 & 1.551 & $10.1 \%$ & $0.891 * * *$ \\
\hline HT1 & 6.117 & 1.327 & $5.1 \%$ & $0.750 * * *$ \\
\hline HT2 & 4.236 & 1.966 & $10.1 \%$ & $0.715 * * *$ \\
\hline HT3 & 5.098 & 1.736 & $7.1 \%$ & $0.842^{* * *}$ \\
\hline BI1 & 5.831 & 1.547 & $10.1 \%$ & $0.876 * * *$ \\
\hline BI2 & 5.573 & 1.339 & $10.1 \%$ & $0.823 * * *$ \\
\hline BI3 & 5.819 & 1.474 & $5.1 \%$ & $0.906 * * *$ \\
\hline
\end{tabular}

Table 7. Indicator statistics of submodel T2

\begin{tabular}{|l|c|c|c|c|}
\hline & Mean & SD & Missing & Loading \\
\hline PE1 & 5.398 & 1.518 & $1.0 \%$ & $0.838^{* * *}$ \\
\hline PE2 & 4.660 & 1.725 & $2.0 \%$ & $0.836 * * *$ \\
\hline PE3 & 4.929 & 1.626 & $1.0 \%$ & $0.893 * * *$ \\
\hline EE1 & 5.760 & 1.581 & $3.0 \%$ & $0.850 * * *$ \\
\hline EE2 & 5.847 & 1.380 & $1.0 \%$ & $0.823 * * *$ \\
\hline EE3 & 5.041 & 1.791 & $2.0 \%$ & $0.849 * * *$ \\
\hline SI1 & 4.143 & 1.933 & $15.2 \%$ & $0.854 * * *$ \\
\hline SI2 & 3.933 & 1.976 & $10.1 \%$ & $0.790 * * *$ \\
\hline SI3 & 4.483 & 1.854 & $12.1 \%$ & $0.839 * * *$ \\
\hline HM1 & 5.255 & 1.452 & $1.0 \%$ & $0.855^{* * *}$ \\
\hline HM2 & 5.242 & 1.596 & $4.0 \%$ & $0.891 * * *$ \\
\hline HM3 & 4.500 & 1.607 & $1.0 \%$ & $0.856 * * *$ \\
\hline HT1 & 5.711 & 1.514 & $2.0 \%$ & $0.831 * * *$ \\
\hline HT2 & 3.847 & 1.912 & $1.0 \%$ & $0.827 * * *$ \\
\hline HT3 & 4.602 & 1.809 & $1.0 \%$ & $0.816 * * *$ \\
\hline BI1 & 5.677 & 1.566 & $3.0 \%$ & $0.907 * * *$ \\
\hline BI2 & 4.732 & 1.693 & $2.0 \%$ & $0.878^{* * *}$ \\
\hline BI3 & 5.436 & 1.485 & $5.1 \%$ & $0.864 * * *$ \\
\hline
\end{tabular}

\subsection{Changes in construct scores}

In terms of the changes in construct scores, Table 8 first reports the means and standard deviations (SD) of 
the unstandardised construct scores at T1 and T2. As means show, the participants had relatively high scores in the case of all the constructs at both $\mathrm{T} 1$ and $\mathrm{T} 2$, but the scores seemed to decline from T1 to T2. The statistical significance of these changes was tested by using both parametric and nonparametric testing because most of the compared means were not found to be normally distributed. The results of the parametric tests are reported in Table 9, whereas the results of the nonparametric tests are reported in Table 10. As the results show, the changes in the construct mean scores were found to be statistically significant in the case of effort expectancy, social influence, hedonic motivation, habit, and behavioural intention, whereas in the case of performance expectancy, the statistical significance of the change suggested by the parametric testing could not be quite confirmed by the nonparametric testing.

Table 8. Construct scores

\begin{tabular}{|l|c|c|c|c|}
\hline \multirow{2}{*}{} & \multicolumn{2}{|c|}{ T1 } & \multicolumn{2}{c|}{ T2 } \\
\cline { 2 - 5 } & Mean & SD & Mean & SD \\
\hline PE & 5.391 & 1.273 & 5.022 & 1.373 \\
\hline EE & 6.043 & 1.058 & 5.589 & 1.303 \\
\hline HM & 4.752 & 1.560 & 4.211 & 1.484 \\
\hline HT & 5.615 & 1.087 & 5.010 & 1.332 \\
\hline BI & 5.240 & 1.226 & 4.854 & 1.406 \\
\hline
\end{tabular}

Table 9. Parametric testing of the changes in construct scores

\begin{tabular}{|l|c|c|c|c|c|}
\hline \multirow{2}{*}{} & \multicolumn{2}{|c|}{ Change } & \multicolumn{3}{c|}{ Paired samples t-test } \\
\cline { 2 - 6 } & Mean & SD & t & df & p \\
\hline PE & -0.369 & 1.403 & -2.617 & 98 & 0.010 \\
\hline EE & -0.455 & 1.364 & -3.315 & 98 & 0.001 \\
\hline SI & -0.540 & 1.486 & -3.619 & 98 & $<0.001$ \\
\hline HM & -0.605 & 1.279 & -4.710 & 98 & $<0.001$ \\
\hline HT & -0.386 & 1.373 & -2.798 & 98 & 0.006 \\
\hline BI & -0.444 & 1.412 & -3.131 & 98 & 0.002 \\
\hline
\end{tabular}

Table 10. Nonparametric testing of the changes in construct scores

\begin{tabular}{|l|c|c|}
\hline \multirow{2}{*}{} & \multicolumn{2}{|c|}{ Signed-rank test } \\
\cline { 2 - 3 } & $\mathbf{Z}$ & $\mathbf{p}$ \\
\hline PE & -1.885 & 0.059 \\
\hline EE & -3.341 & 0.001 \\
\hline SI & -3.819 & $<0.001$ \\
\hline HM & -4.707 & $<0.001$ \\
\hline HT & -2.902 & 0.004 \\
\hline BI & -3.291 & 0.001 \\
\hline
\end{tabular}

\subsection{Changes in effect sizes}

In terms of the changes in effect sizes, Table 11 reports the estimated standardised size of each effect at both $\mathrm{T} 1$ and $\mathrm{T} 2$ as well as its $95 \%$ confidence interval (CI). As can be seen, the estimated size of the effects of performance expectancy and effort expectancy on behavioural intention at $\mathrm{T} 1$ did not fall within the $95 \%$ $\mathrm{CI}$ of the estimated size of the same effects at $\mathrm{T} 2$, thus suggesting that the changes in the size of these effects from $\mathrm{T} 1$ to $\mathrm{T} 2$ were statistically significant. More specifically, the effect of performance expectancy seemed to become weaker over time, whereas the effect of effort expectancy seemed to become stronger over time.

Table 11. Changes in effect sizes

\begin{tabular}{|l|c|c|c|c|}
\hline & \multicolumn{2}{|c|}{ T1 } & \multicolumn{2}{c|}{ T2 } \\
\cline { 2 - 5 } & Size & 95\% CI & Size & 95\% CI \\
\hline PE $\rightarrow$ BI & 0.381 & {$[0.170,0.568]$} & 0.111 & {$[-0.102,0.316]$} \\
\hline $\mathbf{E E ~} \rightarrow$ BI & 0.031 & {$[-0.102,0.182]$} & 0.300 & {$[0.157,0.454]$} \\
\hline $\mathbf{S I} \rightarrow$ BI & 0.031 & {$[-0.088,0.134]$} & 0.077 & {$[-0.058,0.206]$} \\
\hline $\mathbf{H M ~} \rightarrow$ BI & 0.216 & {$[0.035,0.379]$} & 0.224 & {$[0.077,0.377]$} \\
\hline $\mathbf{H T} \rightarrow$ BI & 0.311 & {$[0.112,0.498]$} & 0.306 & {$[0.111,0.521]$} \\
\hline
\end{tabular}

\section{Discussion and conclusions}

In this study, we examined the potential changes in the use intention of digital wellness technologies and its antecedents over time, which have been overlooked in prior IS literature. The examination was done in the case of the young elderly segment and physical activity logger applications by using UTAUT2 as the theoretical foundation. We found that our research model performed very well in explaining use intention after both about four months and about 12 months of using the application by being able to explain about $71 \%$ of its variance at $\mathrm{T} 1$ and about $77 \%$ of its variance at $\mathrm{T} 2$ as well as having acceptable reliability and validity at both construct and indicator levels. The most consistent effects of the antecedent constructs on use intention were found to be those of hedonic motivation and habit, which were found to be positive and statistically significant at both the time points.

In terms of the changes in use intention and its antecedents over time, the most notable change concerned the construct scores, which were found to have declined from $\mathrm{T} 1$ to $\mathrm{T} 2$ in the case of all the constructs except for performance expectancy (cf. Tables 8-10). In other words, the longer the participants used the application, the more effortful and less fun they perceived the use to be, the weaker was the perceived social pressure towards the use, and the less habitual the 
use became. Consequently, also the intention to use the application became weaker over time. These changes are largely in line with theories like the lived informatics model of personal informatics [24], which suggest that the use of personal informatics or self-tracking technologies, such as physical activity logger applications, is often characterised by lapses in their use. In this study, we could not explicitly measure such lapsing behaviour because, for example, if a participant stopped logging his or her physical activities, we did not know whether this was due to a lapse in the use of the application or due to the participant being physically inactive. In addition, the lapsing behaviour itself was likely biased by the fact that the participants were instructed to keep making regular loggings while they remained in the research program. However, without such bias and with the measurements being possible, it can be speculated that many participants would likely have evinced lapses in the use of the application, as implied by the strong declines in use intention.

An additional change in the antecedents of use intention, or more specifically the effects of these antecedents on use intention, concerned the effects of performance expectancy and effort expectancy, of which the former was found to become weaker over time and the latter stronger over time (cf. Table 11). This finding can be seen to be linked to the nature of physical activity logger applications as a digital wellness technology that is typically used on a daily basis, thus causing its use to easily become an integral part of the everyday life and routines of its users. As the use of the application becomes more and more routinised over time, the users are likely to focus less on thinking why they are actually using the technology in question in terms of its performance and utilitarian benefits, and more on how easy and effortless its use is in their everyday life, thus decreasing the importance of performance expectancy and increasing the importance of effort expectancy as antecedents of use intention.

In addition to promoting the theoretical understanding on the use of digital wellness technologies among elderly people, the aforementioned findings also have some important practical implications for the providers of various digital wellness technology products and services. Most importantly, they suggest that the providers should not simply act as passive observers of the use of their products and services but aim to actively promote the positive perceptions and the habitual use of these products and services among the users in order to avoid potential declines in use intention and lapses in use over time. This seems to be especially important in the case of the perceptions concerning hedonic motivation, which was found to be the antecedent of use intention whose scores declined most strongly over time and whose effects on use intention also remained very consistent in terms of not changing from one point in time to another. Two examples of the potential approaches that the providers could use to promote these perceptions over time are gamification [43]-[44] and exergaming [45]-[47]. Of course, the perceptions concerning performance expectancy and effort expectancy should not be ignored either, although especially the scores of performance expectancy were not found to decline so strongly over time, and the effects of both performance expectancy and effort expectancy on use intention were also found to be more inconsistent. The most obvious ways to promote these perceptions are regular application updates that make the applications more useful and easier to use for the users. In contrast, the perceptions concerning social influence did not seem to be so relevant in the case of physical activity logger applications and the young elderly segment because although the scores of this antecedent were also found to decline strongly over time, its effects on use intention remained very weak.

\section{Limitations and future research}

This study can be considered to have three main limitations. First, the study focused on the specific case of physical activity logger applications and the Finnish young elderly segment, which is why future studies are called for to examine the generalisability of its findings to other types of digital wellness technologies and to the elderly population in general. Second, the research setting of the study does not fully correspond to the real-life market environment in which consumers make decisions on technology acceptance and use. For example, the participants were provided for free both the application as well as the training and support for setting up and using it. Without these, factors like facilitating conditions and price value, which were omitted from the research model of this study, may also play an important part as antecedents of use intention and use behaviour. Third, there were also some participants who left the research program already before $\mathrm{T} 1$ or between $\mathrm{T} 1$ and $\mathrm{T} 2$, and, thus, had to be omitted from the sample of this study. Although their reasons for leaving were not necessarily related to the used physical activity logger application, at least some of them may also have been individuals who would have reported very low scores in terms of use intention and its antecedents and whose omission, consequently, may have caused some bias in the data. In our future studies, we aim to address the aforementioned limitations and to augment the preliminary results of this study by refining our research model as well as collecting data from more participants and over a longer period of time as our research program progresses. 


\section{References}

[1] W. J. Chodzko-Zajko, D. N. Proctor, M. A. Fiatarone Singh, C. T. Minson, C. R. Nigg, G. J. Salem, and J. S. Skinner, "Exercise and physical activity for older adults," Medicine \& Science in Sports \& Exercise, vol. 41, no. 7, 2009, pp. $1510-1530$.

[2] F. Sun, I. J. Norman, and A. E. While, "Physical activity in older people: A systematic review," BMC Public Health, vol. 13, 2013, Art no. 449.

[3] World Health Organization, Global Recommendations on Physical Activity for Health, Geneva, Switzerland: WHO Press, 2010.

[4] M. Aubertin-Leheudre and Y. Rolland, "The importance of physical activity to care for frail older adults during the COVID-19 pandemic," Journal of the American Medical Directors Association, vol. 21, no. 7, 2020, pp. 973-976.

[5] C. M. Said, F. Batchelor, and G. Duque, "Physical activity and exercise for older people during and after the coronavirus disease 2019 pandemic: A path to recovery," Journal of the American Medical Directors Association, vol. 21, no. 7, 2020, pp. 977-979.

[6] W. Sepúlveda-Loyola, I. Rodríguez-Sánchez, P. PérezRodríguez, F. Ganz, R. Torralba, D. V. Oliveira, and L. Rodríguez-Mañas, "Impact of social isolation due to COVID19 on health in older people: Mental and physical effects and recommendations," Journal of Nutrition, Health \& Aging, vol. 24, no. 9, 2020, pp. 938-947.

[7] M. Yamada, Y. Kimura, D. Ishiyama, Y. Otobe, M. Suzuki, S. Koyama, T. Kikuchi, H. Kusumi, and H. Arai, "Effect of the COVID-19 epidemic on physical activity in community-dwelling older adults in Japan: A cross-sectional online survey," Journal of Nutrition, Health \& Aging, vol. 24, no. 9, 2020, pp. 948-950.

[8] M. Changizi and M. H. Kaveh, "Effectiveness of the mHealth technology in improvement of healthy behaviors in an elderly population-A systematic review," mHealth, vol. 3, no. 11, 2017, Art no. 51 .

[9] S. Muellmann, S. Forberger, T. Möllers, E. Bröring, H. Zeeb, and C. R. Pischke, "Effectiveness of eHealth interventions for the promotion of physical activity in older adults: A systematic review," Preventive Medicine, vol. 108, 2018, pp. 93-110.

[10] S. Elavsky, L. Knapova, A. Klocek, and D. Smahel, "Mobile health interventions for physical activity, sedentary behavior, and sleep in adults aged 50 years and older: A systematic literature review," Journal of Aging and Physical Activity, vol. 27, no. 4, 2019, pp. 565-593.

[11] S. Stockwell, P. Schofield, A. Fisher, J. Firth, S. E. Jackson, B. Stubbs, and L. Smith, "Digital behavior change interventions to promote physical activity and/or reduce sed- entary behavior in older adults: A systematic review and meta-analysis," Experimental Gerontology, vol. 120, 2019, pp. $68-87$.

[12] D. Yerrakalva, D. Yerrakalva, S. Hajna, and S. Griffin, "Effects of mobile health app interventions on sedentary time, physical activity, and fitness in older adults: Systematic review and meta-analysis," Journal of Medical Internet Research, vol. 21, no. 11, 2019, Art. no. e14343.

[13] C. Carlsson and P. Walden, "Digital wellness for young elderly: Research methodology and technology adaptation," Proceedings of the $28^{\text {th }}$ Bled eConference, Kranj, Slovenia: Moderna organizacija, 2015, pp. 239-250.

[14] C. Carlsson and J. P. Carlsson, "Interventions to form wellness routines among young elderly," Proceedings of the $29^{\text {th }}$ Bled eConference, Kranj, Slovenia: Moderna organizacija, 2016, pp. 406-418.

[15] C. Carlsson and P. Walden, "Digital wellness services for young elderly - A missed opportunity for mobile services," Journal of Theoretical and Applied Electronic Commerce Research, vol. 11, no. 3, 2016, pp. 20-34.

[16] C. Carlsson and P. Walden, "Digital coaching to build sustainable wellness routines for young elderly," Proceedings of the $30^{\text {th }}$ Bled eConference, Maribor, Slovenia: University of Maribor Press, 2017, pp. 57-70.

[17] C. Walden and A. Sell, "Wearables and wellness for the young elderly - Transforming everyday lives?" Proceedings of the $30^{\text {th }}$ Bled eConference, Maribor, Slovenia: University of Maribor Press, 2017, pp. 637-650.

[18] H. Allmér, "Digital wellness services' servicescape for young elderly," Proceedings of the $31^{\text {st }}$ Bled eConference, Maribor, Slovenia: University of Maribor Press, 2018, pp. $159-170$

[19] C. Carlsson and P. Walden, "Digital wellness services: Key to better quality of life for young elderly," Proceedings of the $31^{\text {st }}$ Bled eConference, Maribor, Slovenia: University of Maribor Press, 2018, pp. 249-261.

[20] C. Carlsson and P. Walden, "Digital support to guide physical activity - Augmented daily routines for young elderly," Proceedings of the $32^{\text {nd }}$ Bled eConference, Maribor, Slovenia: University of Maribor Press, 2019, pp. 783-802.

[21] C. Carlsson, T. Kari, M. Makkonen, L. Frank, and P. Walden, "Sustainable physical activity programs for young elderly - A fuzzy analytic hierarchy process approach," Proceedings of the $33^{\text {rd }}$ Bled eConference, Maribor, Slovenia: University of Maribor Press, 2020, pp. 423-437.

[22] C. Carlsson, T. Kari, M. Makkonen, L. Frank, and P. Walden, "Sustained adoption of systematic physical activity programs for young elderly - A developed UTAUT approach," Proceedings of the $33^{\text {rd }}$ Bled eConference, Maribor, Slovenia: University of Maribor Press, 2020, pp. 439-453. 
[23] E. Kettunen, T. Kari, M. Makkonen, L. Frank, and W. Critchley, "Young elderly and digital coaching: A quantitative intervention study on exercise self-efficacy," Proceedings of the $33^{\text {rd }}$ Bled eConference, Maribor, Slovenia: University of Maribor Press, 2020, pp. 469-484.

[24] D. A. Epstein, A. Ping, J. Fogarty, and S. A. Munson, "A lived informatics model of personal informatics," Proceedings of the 2015 ACM International Joint Conference on Pervasive and Ubiquitous Computing, New York, NY, USA: ACM, 2015, pp. 731-742.

[25] V. Venkatesh, J. Y. L. Thong, and X. Xu, "Consumer acceptance and use of information technology: Extending the unified theory of acceptance and use of technology," MIS Quarterly, vol. 36, no. 1, 2012, pp. 157-178.

[26] Wellmo, "Wellmo mobile health platform," Helsinki, Finland: Mobile Wellness Solutions MWS Oy. Available at https://www.wellmo.com (accessed July 1, 2020).

[27] V. Venkatesh, M. G. Morris, G. B. Davis, and F. D. Davis, "User acceptance of information technology: Toward a unified view," MIS Quarterly, vol. 27, no. 3, 2003, pp. $425-478$.

[28] S. Yuan, W. Ma, S. Kanthawala, and W. Peng, "Keep using my health apps: Discover users' perception of health and fitness apps with the UTAUT2 model," Telemedicine and e-Health, vol. 21, no. 9, 2015, pp. 735-741.

[29] P. K. Beh, Y. Ganesan, M. Iranmanesh, and B. Foroughi, "Using smartwatches for fitness and health monitoring: The UTAUT2 combined with threat appraisal as moderators," Behaviour \& Information Technology, 2019.

[30] P. Duarte and J. C. Pinho, "A mixed methods UTAUT2based approach to assess mobile health adoption," Journal of Business Research, vol. 102, 2019, pp. 140-150.

[31] M. S. Talukder, R. Chiong, Y. Bao, and B. H. Malik, "Acceptance and use predictors of fitness wearable technology and intention to recommend," Industrial Management \& Data Systems, vol. 119, no. 1, 2019, pp. 170-188.

[32] N. Dhiman, N. Arora, N. Dogra, and A. Gupta, "Consumer adoption of smartphone fitness apps: An extended UTAUT2 perspective," Journal of Indian Business Research, vol. 12 , no. 3,2020 , pp. 363-388.

[33] I. M. Macedo, "Predicting the acceptance and use of information and communication technology by older adults: An empirical examination of the revised UTAUT2," Computers in Human Behavior, vol. 75, 2017, pp. 935-948.

[34] C. M. Ringle, S. Wende, and J.-M. Becker, "SmartPLS 3," Boenningstedt, Germany: SmartPLS GmbH. Available at https://www.smartpls.com (accessed July 1, 2020).
[35] J. Hair, C. L. Hollingsworth, A. B. Randolph, and A. Y. L. Chong, "An updated and expanded assessment of PLSSEM in information systems research," Industrial Management \& Data Systems, vol. 117, no. 3, 2017, pp. 442-458.

[36] E. Roemer, "A tutorial on the use of PLS path modeling in longitudinal studies," Industrial Management \& Data Systems, vol. 116, no. 9, 2016, pp. 1901-1921.

[37] F. Wilcoxon, "Individual comparisons by ranking methods," Biometrics Bulletin, vol. 1, no. 6, 1945, pp. 80-83.

[38] S. S. Shapiro and M. B. Wilk, "An analysis of variance test for normality (complete samples)," Biometrika, vol. 52, no. 3-4, 1965, pp. 591-611.

[39] J. F. Hair, Jr., G. T. M. Hult, C. M. Ringle, and M. Sarstedt, A Primer on Partial Least Squares Structural Equation Modeling (PLS-SEM), $2^{\text {nd }}$ ed. Thousand Oaks, CA, USA: Sage, 2016.

[40] M. Makkonen, T. Kari, and L. Frank, "Applying UTAUT2 to explain the use of physical activity logger applications among young elderly," Proceedings of the $33^{\text {rd }}$ Bled eConference, Maribor, Slovenia: University of Maribor Press, 2020, pp. 567-582.

[41] C. Fornell and D. F. Larcker, "Evaluating structural equation models with unobservable variables and measurement error," Journal of Marketing Research, vol. 18, no. 1, 1981, pp. 39-50.

[42] J. C. Nunnally and I. H. Bernstein, Psychometric Theo$r y, 3^{\text {rd }}$ ed. New York, NY, USA: McGraw-Hill, 1994.

[43] T. Kari, J. Piippo, L. Frank, M. Makkonen, and P. Moilanen, "To gamify or not to gamify? Gamification in exercise applications and its role in impacting exercise motivation," Proceedings of the $29^{\text {th }}$ Bled eConference, Kranj, Slovenia: Moderna organizacija, 2016, pp. 393-405.

[44] J. Koivisto and J. Hamari, "The rise of motivational information systems: A review of gamification research," International Journal of Information Management, vol. 45, 2019, pp. 191-210.

[45] T. Kari, "Can exergaming promote physical fitness and physical activity: A systematic review of systematic reviews," International Journal of Gaming and ComputerMediated Simulations, vol. 6, no. 4, 2014, pp. 59-77.

[46] T. Kari and M. Makkonen, "Explaining the usage intentions of exergames," Proceedings of the $35^{\text {th }}$ International Conference on Information Systems, Atlanta, GA, USA: Association for Information Systems, 2014.

[47] D. L. Kappen, P. Mirza-Babaei, and L. E. Nacke, "Older adults' physical activity and exergames: A systematic review," International Journal of Human-Computer Interaction, vol. 35, no. 2, 2019, pp. 140-167. 